\title{
The Exploration of Teaching and Talents Cultivation of Rehabilitation Therapeutics
}

\author{
Han Qiao ${ }^{\mathrm{a}}$, Cheng Meng ${ }^{\mathrm{b}}$, and Zhao Chunshan ${ }^{\mathrm{c}, *}$ \\ School of BeiHua University, Jilin 132013, China \\ a963683570@qq.com, ${ }^{b} 531513191 @ q q . c o m,{ }^{c} 476185637 @ q q . c o m$
}

Keywords: Rehabilitation Therapeutics; teaching; talent; cultivate

Abstract: Rehabilitation therapeutics is an emerging discipline, which is mainly used to cultivate professional technical talents engaged in the task of clinical rehabilitation therapy. From the perspective of the current situation of our country, the development of rehabilitation therapeutics is relatively late, lack of experience. With people's requirement concerning the condition of the disease rehabilitation is constantly increasing, the talents specialized in the rehabilitation therapeutics have become the urgent need of advanced talents of in our country at present, so it is particularly important to carry out the series of courses of rehabilitation therapeutics and cultivate the ability of talents thereof.

\section{Introduction}

With the continuous development of economy, people's living quality constant improving, the issue concerning the rehabilitation of the patients with various body as well as limbs diseases has received extensive attention, people pursue better means of rehabilitation treatment, which could make the disease rehabilitated in a better and faster way. It requires that we should focus on the mode of modernized medicine and guide the prevention, diagnosis and rehabilitation of diseases in order to reduce the occurrence of diseases, promote the recovery of the disease to the maximum extent. Facing such a situation, it becomes increasingly important to set up the undergraduate professional courses of rehabilitation therapeutics for the professional teaching related to it as well as the cultivation of the relevant talents of rehabilitation therapy, especially the cultivation of the talents related to the advanced rehabilitation therapy.

\section{The Shortage of Rehabilitation Therapy Talents and Its Great Need}

The chairman of the Chinese Rehabilitation Medicine Conference Fang Guo'en says that China has become the country that has the largest population of the old in the world, also one of the country with the ageing population developing the fastest, an annual increase of the elderly population aging more than 60 is 10 million, ranging from sixty percent to seventy percent of which all need the rehabilitation therapy services. However, the proportion of rehabilitation therapists in China among the basic group of people is about 0.4:100000, and the number of rehabilitation therapists in the developed countries is ranging from 40 to 70 per 100000 people [1]. It could be seen that a terrible shortage of rehabilitation of talents exists in our country, the development of 
rehabilitation education is relatively slow comparing with the developed countries, in order to improve this situation, it requires us improve the undergraduate education of rehabilitation therapy, set up the profession of the rehabilitation treatment in each university of medical sciences as well as the comprehensive colleges and universities, cultivate more talents of rehabilitation treatment, whose development prospect is promising.

\section{Clarify the Teaching Objectives of Rehabilitation Therapeutics}

This profession cultivates the rehabilitation therapists that satisfy the needs of the development of China's medical and health undertakings, have a solid foundation of rehabilitation medicine basic theory and the stronger rehabilitation treatment technology, possess the advantage of combining Chinese and western medicine features, with relatively strong interpersonal communication skills and good professional ethics, can carry out the work of rehabilitation evaluation and rehabilitation treatment at institutions of medical treatment or rehabilitation or sanatoriums of all levels, in addition, it fosters the applied senior specialized talents that can undergo the work of research and development in the institution or company that engaged in rehabilitation medicine engineering study .

\section{The Courses Set up for Rehabilitation Therapeutics}

The major of rehabilitation therapeutics is specialized in the cultivation of rehabilitation therapists, accordingly the curriculum set up is closely centered on the theories as well as basis of various rehabilitation therapy techniques [2]. The main majors as well as professional courses are as follows: functional anatomy, summary of clinical disease, kinesiology of human body, the science of the development of human body, the introduction to rehabilitation medicine, the science of rehabilitation functional evaluation, the science of rehabilitation psychology, speech therapy, homework therapy, physical therapy, the science of community rehabilitation, rehabilitation nursing science, musculoskeletal rehabilitation science, neurological rehabilitation science, clinical rehabilitation engineering science, traditional rehabilitation methodology, children's rehabilitation medicine.

\section{Select Suitable Professional Textbooks and Compile the Syllabus of each Course}

The teaching materials are the basis of teaching, the carrier of cultivating talents and imparting knowledge, furthermore, they are one of the main objects of the students' cognition, therefore, the quality of the textbooks is directly related to the specific level of teaching quality accordingly [3]. The teaching quality of the undergraduate courses of rehabilitation therapeutics needs to be improved, the teaching materials are the key. In the recent several years, the usage of the textbooks concerning the major of the rehabilitation therapy has realized that the domestic and foreign advanced teaching materials and experimental guiding books that adapt to the specific circumstances of the university of one's own are chosen, and it sets up the relatively scientific writing, evaluation and selection system of the teaching materials, ensures that the professional teaching materials reflecting a high level, high quality and being suitable to the characteristics of the profession are brought into the classroom. The current textbooks used is a series of rehabilitation therapeutics textbooks that is published by Huaxia Publishing House, they are presided and complied by the domestic well-known experts of rehabilitation therapeutics.

According to the curriculum establishment, organize teachers to prepare to write the syllabus of each course, make it clear that the content needs to be understood, be familiar with and master in each course, meanwhile, determine the respective proportion in the syllabus [4]. According to the 
content of the teaching content, the number of the periods of the theory as well as the internship lessons in each course are determined. According to the requirements of the teaching syllabus, the internship teaching syllabus should be formulated and improved, and the internship rotation plan and the learning content to be finished required during the internship are formulated.

\section{Talent Cultivation and Ability Nurture of Rehabilitation Therapy Profession}

\subsection{Cultivate the Students’ Professional Ethics of Rehabilitation Therapy Profession}

The main service objectives of rehabilitation therapy are the dysfunctional disabled and the elderly, a series of rehabilitation therapy services could be provided to them, make them recovery in a better, faster way, to achieve the health both mentally and physically. In our country, it is easy to become a rehabilitation specialist, but it is not easy to be an excellent rehabilitation specialist. As a result, it is required that the rehabilitation therapists should have the good professional ethics, be willing to help the patients, be willing to sacrifice themselves, really take the patient as the center, then treat the corresponding symptoms by way of the reasonable professional treatment. For the cultivation of the talented person in rehabilitation therapeutics technology among the undergraduate students, which should be paid more attention, it should cultivate the students' professional ethics by adopting the progressive cultivation scheme of "cognition, emotion, action" in accordance with the law of the development of human emotions [5].

\subsection{Ability Nurture of Rehabilitation Therapy Profession}

Facing the extreme shortage of rehabilitation therapy talents, the first task of our country is to cultivate the relevant talents of the rehabilitation profession as much as possible, conducting the nurture of the abilities of all aspects. As is known to all, the education of the rehabilitation therapy profession is the important content as well as the crucial task of modern rehabilitation medicine education, the education of the rehabilitation therapy profession of our country at present can not meet the needs of the continuous development of the rehabilitation medicinal undertakings, it still needs to constant reform and innovation. In recent years, the education of rehabilitation medicine in our country has made considerable development and progress, regarding the ability nurture for the talents of rehabilitation profession, we also put forward the rehabilitation therapy technology professional talents nurture mode of "helping the disabled with love and charity, interacting work with study, integrating class and certificate” [6].

\section{Conclusion}

With the rapid development of rehabilitation therapeutics, there is an increasing demand for rehabilitation therapy technology talents, accordingly the colleges and universities have set up the profession of rehabilitation therapeutics, so as to meet the needs of medical and health institutions at various levels for rehabilitation therapists. However, the undergraduate education of the rehabilitation therapeutics major in our country starts relatively late, which still have a long way to go. It is firmly believed that through the continuous efforts, the rehabilitation therapeutics major will be bound to become an important part of China's advanced medical education, which will provide a large number of high-level talents for the development of rehabilitation medicinal undertakings in China. 


\section{Acknowledgements}

This work was financially supported by the Jilin provincial education Department Project (SJJY2 01709) fund. The corresponding author is Zhao Chunshan, Female, (1980-), Doctor's degree.

\section{References}

[1] Xu Shouyu, Lai Pingfan, Lin Xianming, Xie Guangyao, Gao Gengde, Li Junwei. The Fusion of the East and the West Pay Attention to the Practice the Exploration of the Undergraduate Talents Nurture Mode of Rehabilitation Therapeutics Major [J]. Chinese Higher Medical Education, 2012 (04): 17-18.

[2] Zhang Fengren, Li Hongxia. Discussion on the Professional Curriculum Setting of Rehabilitation Therapeutics [J]. Chinese Rehabilitation Theory and Practice 2004,8(10):449.

[3] Fang Yujiao, Zou Qinghua. Experience in Teaching Management of Rehabilitation Technology Conducted in Advanced Vocational Education [J]. China Clinical Rehabilitation,2004,8(14):2651.

[4] Pan Cuihuan, Chen Yan, Ye Zhengmao, Miao Ping. Discussion on the Professional Construction Mode of Rehabilitation Therapeutics [J]. Northwest Medicine Education,2009,17(02):234-235+238.

[5] Jin An'ping, Qiang Gang. Discussion on the Nurturing Thoughts of the Professional Talents of the Rehabilitation Therapy Technology in Higher Vocational Colleges [J]. Massage and Rehabilitation Medicine (the Middle 10 Days of the Journal),2010,1(2)

[6] Luo Zhi'an, Li Fusheng, Chen Zhuoyi, etc. The Construction of the Professional Curriculum System for Rehabilitation Therapy Technology Major Based on the Working Process Guidance [J]. Chinese Rehabilitation Medicine Journal,2010,25(8) 